\title{
Design and Development of Continuous UV-C Light System for Liquid Food Products
}

\author{
Shivashankar Sanganamoni $^{1 *}$, C. Krishna Teja ${ }^{1}$, B. Prabhakar ${ }^{2}$ \\ and Pavuluri Srinivasa Rao ${ }^{1}$
}

\author{
${ }^{1}$ Agricultural and Food Engineering Department, IIT Kharagpur, W.B - 721 302, India \\ ${ }^{2}$ College of Food Technology, VNMKV, Parabhani, Maharastra - 431 401, India \\ *Corresponding author
}

\section{A B S T R A C T}

\begin{tabular}{|l|}
\hline Ke y w o r d s \\
UV-C light, Wave \\
length, Liquid \\
foods, Continuous \\
mode, Pulsed mode.
\end{tabular}

\section{Introduction}

Pasteurization is an effective technology in order to reach safety requirements. However, it has many limitations like cost of the equipment is prohibitive especially for small operations and adverse effects of thermal pasteurization on the food quality. The consumers are demanding for fresh-like products without losing nutritional properties. To prevent the nutritional loss of products, alternative methods such as microbicidal agents, high pressure application, pulsed electric field, irradiation, and aseptic packaging were developed. However there are some disadvantages of these techniques. Loss of ascorbic acid in apple juice was reported by Opstal et al., (2006). The use of PEF treatment causes brightness in the color of orange juice (Min et al., 2003) and its application to industry is limited due to its high cost. Also, as light browning in the color of white grape juice was observed after the high pressure treatment (Daoudi et al., 2002).

Considering these limitations of other techniques, UV-Cradiation can be used as an alternative to other preservation techniques. 
This process does not produce chemical residues (Canitez, 2002). Besides, it is a lowcost operation and effective against many microorganisms (Bintsis et al., 2000).

UVlightisthepartofelectromagneticspectrumw ithwavelengthsrangingfrom 100 -

$400 \mathrm{~nm}$.Itisnonionizing radiation treatment of liquid foods can be done using both continuous and pulsed UV sources. UV light is traditionally sub divided into three categories such as UV-A (Wave length range from $315-400 \mathrm{~nm}$ and this range is responsible for Changes in human skin), UVB (Wave length range from 280 to $315 \mathrm{~nm}$ and can cause skin burning and has the potential to cause skin cancer) and UV-C (Wave length ranges from 200 to $280 \mathrm{~nm}$ and is very well known for its antimicrobial effect). UV-C is used for the decontamination of medical equipment, water treatments, drinking water, water for swimming pools, and surfaced is infection of different fruits and other processing equipment. Application of UV light on various liquid foods like apple cider, orange juice, grape juice, milk and honey have been developed recently.

UV-C radiation germicidal properties are due to the DNA absorption of the UV light which causes crosslinking between the neighbouring pyrimidine nucleoside bases (thymine and cytosine) in the same DNA strand (Miller et al., 1999). Due to this, the DNA transcription and replication is blocked, which compromises cellular functions and leads to cell death (Miller et al., 1999). It has broad microbial action with effective inactivation of viruses, vegetative bacteria, bacterial spores, yeasts and parasites. UV light is a physical rather than a chemical process, which makes it ideal due to ease of maintenance, low operating cost, and operator safety and lack of residue spots treatment.

The application of UV light for liquid foods on large scale has begun in France in 1906 for disinfection of water. However its use in food processing is being studied for minimally processing food product without affecting its nutritional quality. Three categories of food can be treated with UV including liquids, emulsions and liquid with particles or suspensions. Apart from its application, it has a consumer acceptance due to its nonionization radiation compared to gamma radiation. The U.S. FDA has approved UVlight application for pasteurization treatment of fruit juice products in 2000 and the basic criteria set for UV- application is $5 \log$ reductions in number of pathogens present in fruit juices. The UV application can also improve toxicological safety of foods through its ability to reduce toxins such as patuline mycotoxin in apple cider and possibly be reducing the allergenicity of products such as peanut butter. UV light is used in disinfection of surface microflora which includes equipment's which comes in contact with food during processing like conveyors, packaging materials etc. However considering its application on food surfaces like meat products the limited penetration of UV light limits its application for decontamination.

Application of UV light in liquid food products has shown positive results as evident from reduction in number of pathogenic microorganisms. However, the efficacy of UV treatment in liquid foods is dependent on its constituents like pigments, organic solutes and suspended particles which limit the transmission of UV light through the liquid food.

The absorbance of UV light in fruit juices is reported to be significantly more compared to water. Also Vitamin - $\mathrm{C}$ a light sensitive Vitamin degrades in presence of UV light. Hence, both physical and nutritional properties, such as turbidity, absorbance at $254 \mathrm{~nm}$, viscosity, and Vitamin C content are to be considered to develop a treatment system in order to meet the required 
pasteurization standard of a 5-log reduction in the number of the target pathogen of concern for fresh juices.

Different modes of UV treatments can be applied to food products such as continuous mode and pulsed mode. The present study was aimed to design, development and fabrication of continuous UV-C light system for liquid food products.

\section{Materials and Methods}

\section{Design of UV-C Irradiation Chamber (Treatment Chamber)}

A $90 \times 30 \times 30 \mathrm{~cm}$ treatment chamber is made of "Fly Wood material (Both sides coated with paint). The chamber was designed such that the distance of sample from lamp source can be varied. Treatment chamber contains Lamp assembly, Control switch assembly and Holder platform. In order to prevent exposure of UV light to human skin, a cover is placed in front of the system.

\section{Circuit design}

Electrical circuit is constructed such that the lamps can be connected to $240 \mathrm{~V}$ power supply through controlling switches. All precautions has been taken to prevent the short circuit and fluctuations in voltage.

\section{UV-C lamp assembly}

Three $18 \mathrm{~W}$ low pressure mercury vapor UV lamps which emit UV-C light in wave length ranges from 200-300 $\mathrm{nm}$ were purchased from local market. The three lamps are placed in lamp holder mounted at the top of the treatment chamber. The three lamps were connected parallel with separate control switches. Lamps were connected to the circuit through control switch assembly. The total capacity of UV-C system can be obtained as
$18 \mathrm{~W}, 36 \mathrm{~W}$ and $54 \mathrm{~W}$ by using control switches.

\section{Control switch assembly}

A control switch assembly was provided on right side of the UV-C chamber to control the lamps. This assembly consists of three switches placed on switch board. Each switch is independently connected to lamp. Entire assembly is directly connected to $240 \mathrm{~V}$ DC power supply.

\section{Holder platform}

Holder platform is placed inside the UV-C chamber. The main purpose of holder platform is to maintain the different sample distances from lamp source. The plat for misable to move upward or downward by tray system. Four slots are provided at $8.6 \mathrm{~cm}$, $13.7 \mathrm{~cm}, 18.7 \mathrm{~cm}$ and $22.8 \mathrm{~cm} \mathrm{~cm}$ distance to place holder platform. Petri plate having liquid sample which is to be treated was placed on holder platform. The sample in petri plates will directly exposed to UV-C light. Experiment can be conducted at various sample distances using holder platform to obtain the different rate of UV fluence.

\section{Measurement of UV Fluence}

The amount of UV fluence received at different distances was calculated using Bolton's formula (Bolton, 1999), formula (2.1) in combination with Beer-Lamberts formula (2.2). Pineapple juice was used to measure the amount of fluence at different distances.

$E(x, H)=\frac{\theta}{4 \pi L x}\left(\arctan \left(\frac{\frac{L}{2}+H}{x}\right)+\arctan \left(\frac{\frac{L}{2}-H}{x}\right)(2.1)\right.$

Where, 
$\mathrm{E}(\mathrm{x}, \mathrm{H})$ is the Fluence rate measured in $\mathrm{m}$ $\mathrm{W} / \mathrm{cm}^{2}$ at $(\mathrm{x}, \mathrm{H})$

$\mathrm{H}$ is the center to center distance from lamp to petri dish.

L is length of the UV light source

$\mathrm{x}$ is the radius of the petri dish

$\theta$ is the Source radiant power in Watts

Samples were subjected to different UV dose values. UV dose is the product of exposure time $(\mathrm{t}=$ minute $)$ and average $\mathrm{UV}$ intensity value $\left(\operatorname{Iavg}=\mathrm{mW} / \mathrm{cm}^{2}\right)$.

Average fluence rate was calculated according to an integration of Beer-Lambert Law

Iavg $=\mathrm{I} 0 *(1-\exp (-A \mathrm{e} * \mathrm{~L})) / A \mathrm{~A} * \mathrm{~L}(2.2)$

In this equation, I0 represents the incident light intensity $\left(\mathrm{mW} / \mathrm{cm}^{2}\right)$, Ae value indicates the absorption coefficient $(1 / \mathrm{cm})$ and $\mathrm{L}$ is the path length $(\mathrm{cm})$.

\section{Results and Discussion}

Design of lab scale continuous UV-system

A lab scale UV system was designed so as to conduct the treatments at different heights from the lamp source. The setup is represented in the following figures. The figures 1, 2, 3 and 4 represent the front view, side view, top view and $3-\mathrm{D}$ view of the setup respectively.

\section{Development of lab scale UV chamber}

The lab scale setup was made with plywood and a coating with paint was given to the setup. The platform is detachable and can be adjusted such that the distance from the lamp source can be varied. Three 18 Watt low pressure UV-lamps (200-300 nm wave lengths) was mounted at the top which is connected to a switch which was mounted to the side wall of the setup.

Table.1 UV fluence at different distance and exposure times

\begin{tabular}{|c|c|c|}
\hline Distance (cm) & Exposure time (min) & Pineapple dose $\left(\mathrm{mJ} / \mathrm{cm}^{2}\right)$ \\
\hline 8.6 & 5 & $183 \pm 2.8$ \\
\hline 8.6 & 10 & $366 \pm 2.5$ \\
\hline 8.6 & 15 & $549 \pm 3.1$ \\
\hline 13.7 & 5 & $102 \pm 2.2$ \\
\hline 13.7 & 10 & $204.6 \pm 2.3$ \\
\hline 13.7 & 15 & $306.9 \pm 3.3$ \\
\hline 18.6 & 5 & $49 \pm 1.5$ \\
\hline 18.6 & 10 & $131 \pm 1.1$ \\
\hline 18.6 & 15 & $198 \pm 1.3$ \\
\hline 22.8 & 5 & $48.8 \pm 2.5$ \\
\hline 22.8 & 10 & $98.2 \pm 2.9$ \\
\hline 22.8 & 15 & $147 \pm 3.8$ \\
\hline
\end{tabular}

Values are presented with mean \pm standard deviation $(n=4)$ 
Fig.1 Front view of the experimental set up

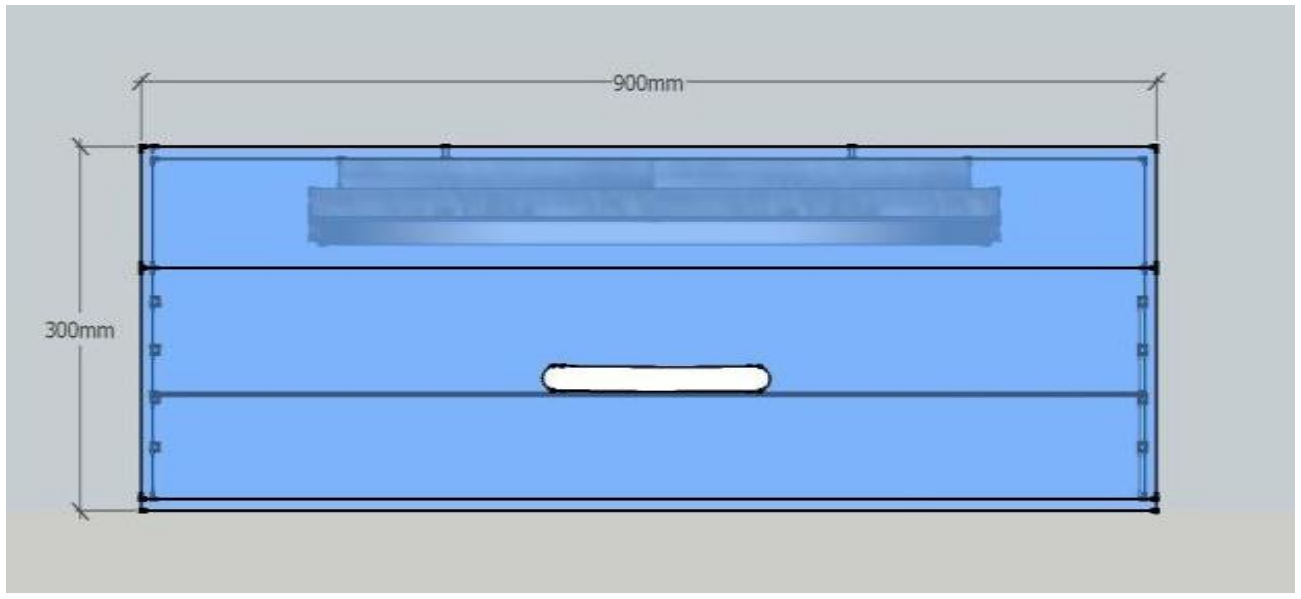

Fig.2 Side view of the experimental setup

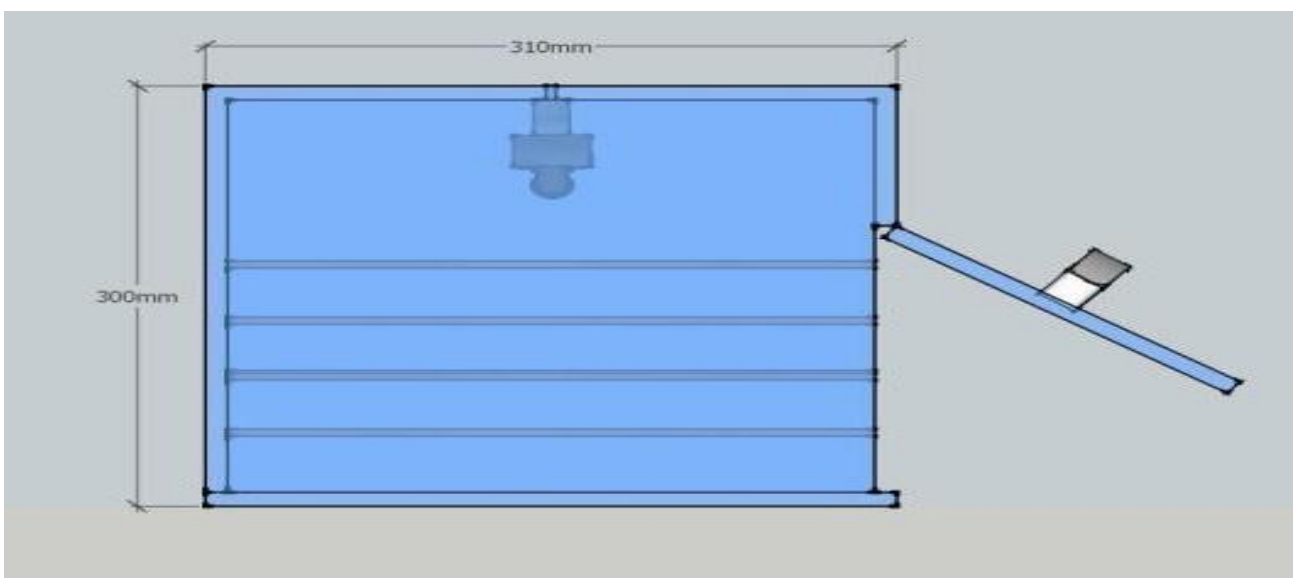

Fig.3 To p-view of the experimental setup

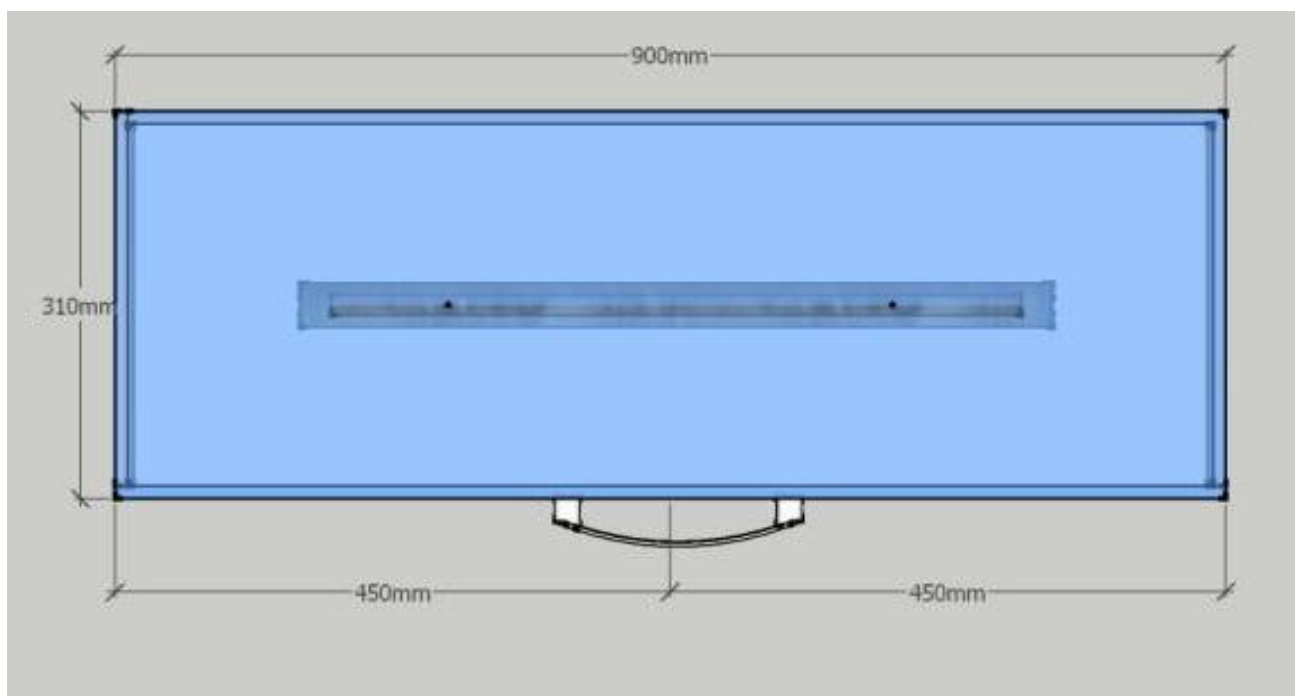


Fig.4 3D-view of the experimental setup

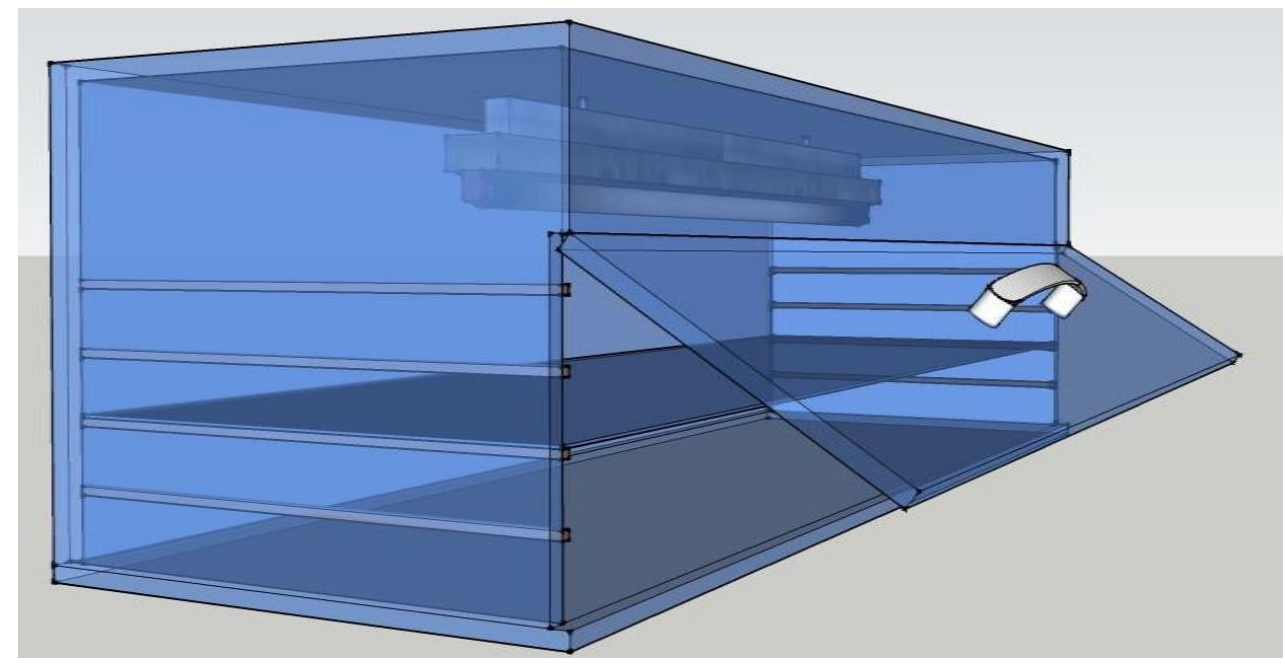

Fig.5 Lab scale treatment chamber after fabrication

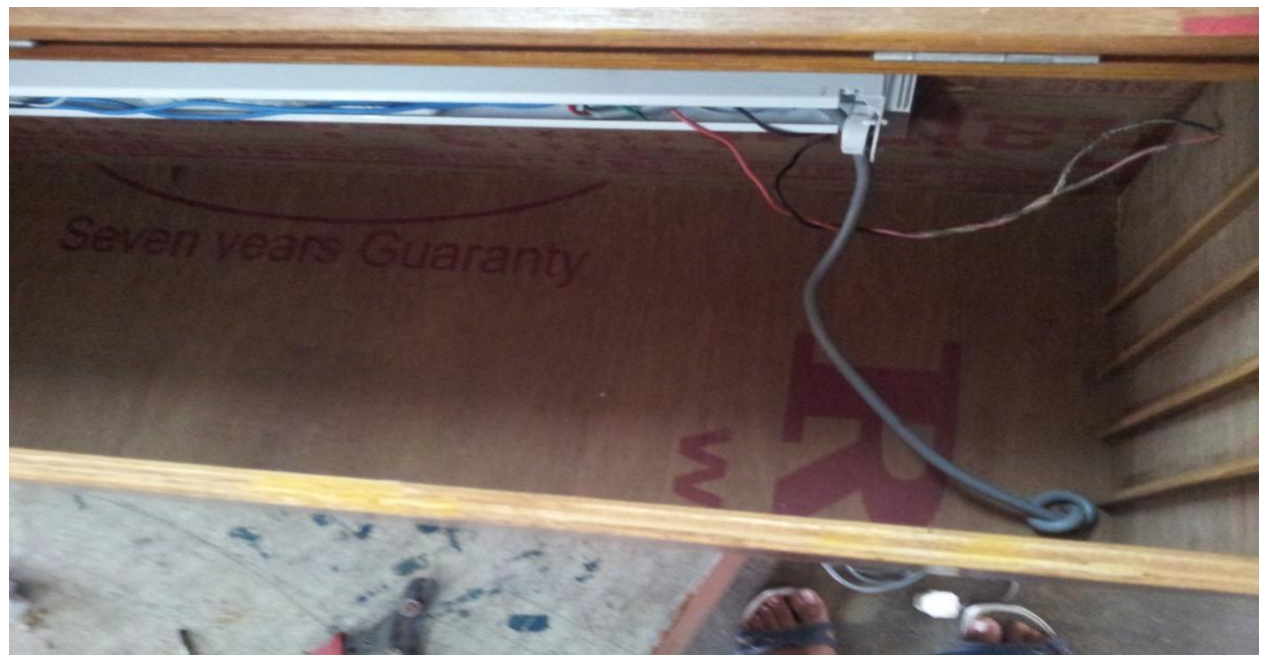

Fig.6 Lab scale treatment chamber after fabrication

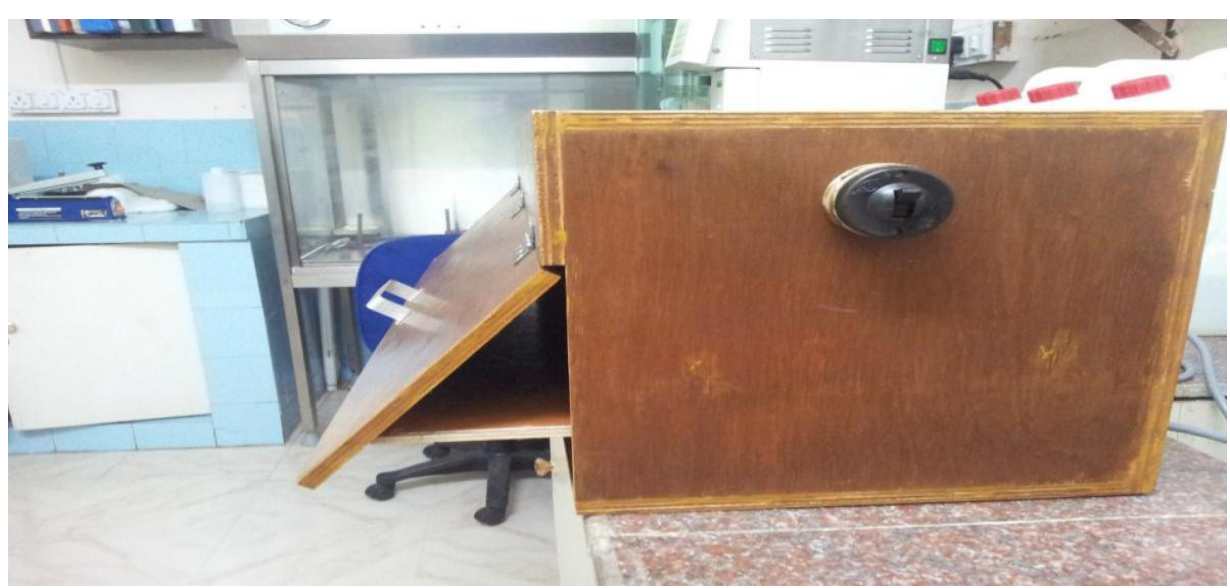


This in turn was connected to the power source. The dimensions of the setup were $90 \mathrm{x}$ $30 \times 30 \mathrm{~cm}$ and the plat form can be mounted at variable distances of $8.6,13.7,18.7$ and $22.8 \mathrm{~cm}$ from the lamp source. The length of each lamp is $58 \mathrm{~cm}$. The final set up is presented in figures 5 and 6.

\section{UV-dosage calculations}

The dosage at different heights of treatments and at variable time of exposure to UV light has been calculated by using the Bolton's formula and Beer Lamberts law. The results have been presented in table 1 .

Lab scale continuous UV- C system was designed and fabricated during the study. After fabrication of system, the UV fluence was measured at different distances and time of exposure for pineapple juice. The setup was used to conduct further experiments.

\section{Acknowledgment}

The authors express sincere thanks to IIT Kharagpur and ministry of MHRD, Govt. of India for providing financial support during the tenure of research work.

\section{References}

Anderson, J. G., Rowan, N. J., MacGregor, S. J., Fouracre, R. A. and Farish, O. (2000). Inactivation of food-borne enteropathogenic bacteria and spoilage fungi using pulsed-light. Plasma Science, IEEE Transactions on Plasma Science, 28(1), 83-88.

Bates, R. P., Morris, J. R. and Crandall,P. G.(2001). Principles andpractices of small-andmedium-scalefruit juiceprocessing. FAOAgriculturalServices Bulletin, 146,135-149.
Begum, M., Hocking, A.D. and Miskelly, D. (2009). Inactivation of food spoilage fungi by ultraviolet (UVC) irradiation. International Journal Food Microbiology, 129, 74-77.

Bintsis, T., Tzanetaki, E.L. and Robinson, R.K., (2000). Existing and potential applications of ultraviolet light in the food industry - a critical review. Journal of the Science of Food and Agriculture, 80, 637-645.

Bolton, J.R. Ultraviolet Applications Handbook, 1st Ed. 1999, Ayr, Ontario, Canada, Bolton Photosciences, Inc.

Bolton, J. R., Linden, K. G., andAsce, M. (2003). Standardization of method for fluence UV dose determination in benchscale UV experiments. Journal of EnvironmentalEngineering, 129(3), 209215.

Canitez N., 2002. Pasteurization of Apple Cider with UV Irradiation. MS Thesis. The University of Maine.

Caron, E., Chevrefils, Jr.G., Barbeau, B., Payment, P. and Prevost, M., 2007. Impact of microparticles on UV disinfection of indigenous aerobic spores. Water Research 41, 4546-4556.

Chang, S.S. and Kang, D.H., 2004. Alicyclobacillus spp. in the fruit juice industry: history characteristics, and current isolation / detection procedures. Critical Reviews in Microbiology, 30, 55-74.

Daoudi, L., Quevedo, J.M., Trujillo, J., Capdevila, F., Bartra, E., Mínguez, S. and Guamis, B., 2002. Effects of highpressure treatment on the sensory quality of white grape juice. High Pressure Research. 22,705-709.

Dock, L.L., 1999. Development of thermal and non-thermal preservation methods for producing microbially safe apple cider. Ph.D. Thesis. Purdue University, West Lafayette, IN, USA. 
Guerero-Beltran, J. A., \&Barbosa-Canovas, G. V. (2005). Reduction ofSaccharomyces cerevisiae, Escherichia coliand Listeria innocuain apple juicebyultraviolet light.Journal of Food Process Engineering,28, 437-452.

Pan, J., Vicente, A.R., Martínez, G.A., Chaves, A.R., and Civello, P.M. (2004). Combined use of UV-C irradiation and heat treatment to improve postharvest life of strawberry fruit. Journal of the Science ofFood and Agriculture, 84, 1831-1838.

Koutchma, T., Keller, S., Chirtel, S., \& Parisi, B. (2004). Ultraviolet disinfection of juice products in laminar and turbulent flow reactors. Innovative Food Science and Emerging Technologies, 5(2), 179189.

Koutchma, T., Parisi, B., \& Unluturk, S. K. (2006). Evaluation of UV dose in flowthrough reactors for fresh apple juice and cider. Chemical Engineering Communications, 193(6), 715-728.

Koutchma, T., Parisi, B., \& Patazca, E. (2007). Validation of UV coiled tube reactor for fresh juices. Journal of Environmental Engineering and Science, 6(3), 319-328.

Koutchma,T. (2009). Advances in ultraviolet light technology for non-thermal processing of liquid foods. Food and Bioprocess Technology, 2(2), 138-155.
Kozempel, M., McAloon, A., and Yee, W. (1998). The cost of pasteurizing apple cider. Food Technology, 52(1), 50-52.

Miller, R.V., Jeffrey, W., Mitchell, D. and Elasri, M., 1999. Bacterial responses to ultraviolet light, American Society of Microbiology News 65(8), 535-541.

Min, S., Jin, Z.T., Min, S.K., Yeom, H. and Zhang, Q.H., 2003. Commercial-Scale pulsed electric field processing of orange juice. Journal of Food Science: Food Chemistry and Toxicology, 68(4):1265-1271.

Opstal, I.V., Bagamboula, C.F., Theys, T., Vanmuysen, S.C.M. and Michiels, C.W., 2006. Inactivation of Escherichia coli and Shigella in acidic fruit and vegetable juices by peroxidase systems. Journal of Applied Microbiology, 101, 242-250.

Tandon, K., Worobo, R. W., Churey, J. J., and Padilla-Zakour,O. I. (2003). Storagequality ofpasteurized and UV treated apple cider.Journal ofFood Processing, 27(1), 21-35.

Tran, M.T.T. and Farid, M., 2004. Ultraviolet treatment of orange juice. Innovative Food Science and Emerging Technologies 5,495-502.

Wang, T., Macgregor, S.J., Anderson, J.G. and Woolsey, G.A., 2005. Pulsed ultraviolet inactivation spectrum of Escherichia coli. Water Research 39, 2921-292.

\section{How to cite this article:}

Shivashankar Sanganamoni, C. Krishna Teja, B. Prabhakar and Pavuluri Srinivasa Rao. 2017. Design and Development of Continuous UV-C Light System for Liquid Food Products. Int.J.Curr.Microbiol.App.Sci. 6(6): 2232-2239. doi: https://doi.org/10.20546/ijcmas.2017.606.265 